\title{
UNU-INWEH
}

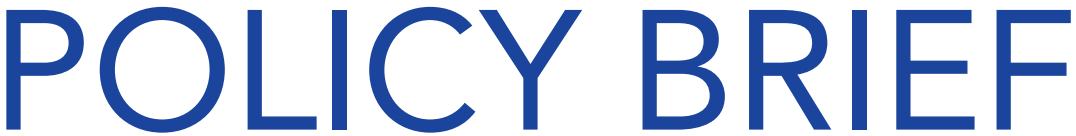

\section{SUSTAINABLE DEVELOPMENT GOALS AND THE ECONOMICS OF LAND DEGRADATION}

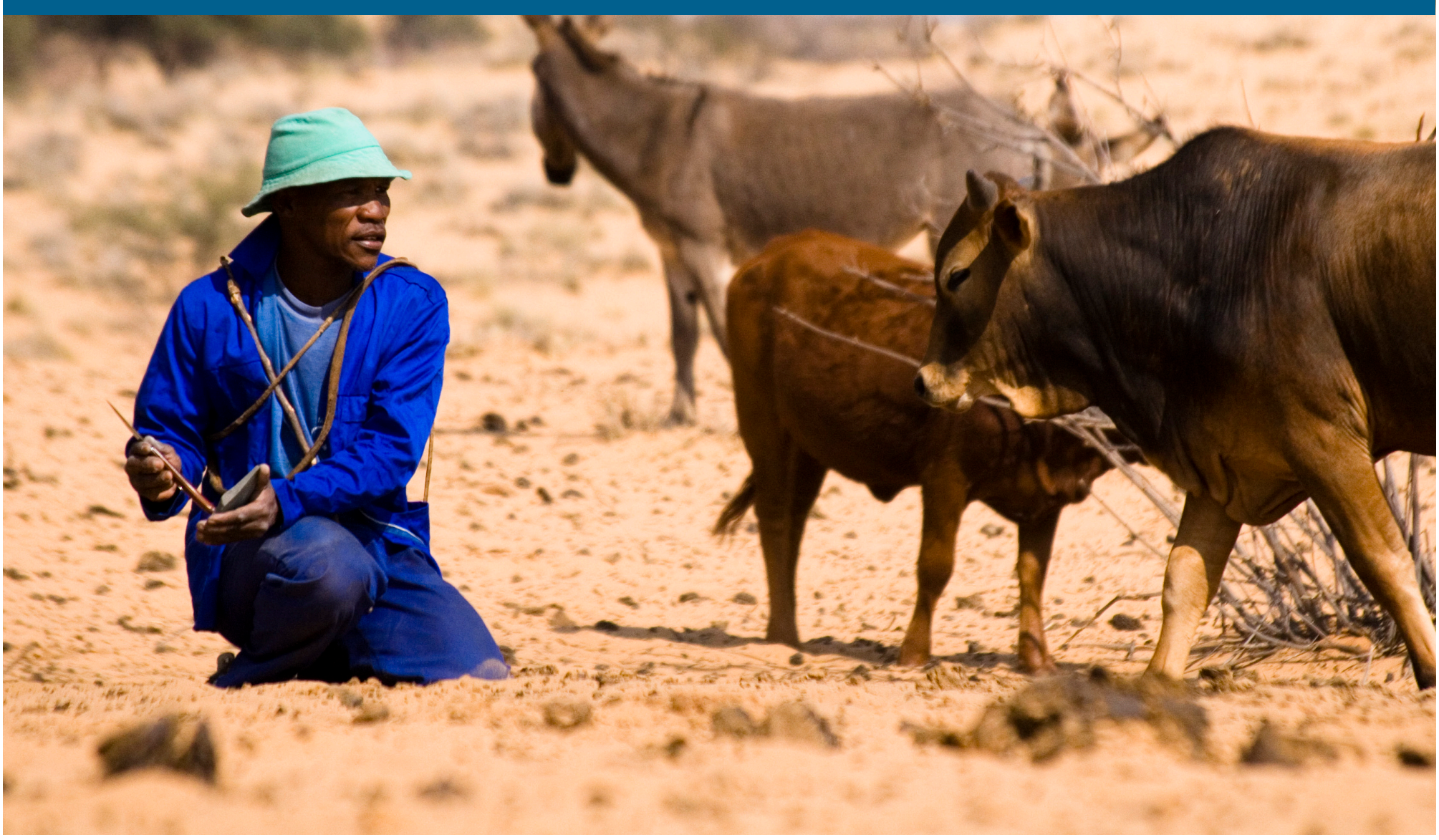

\section{Findings}

- $10 \%$ to $20 \%$ of land globally is degraded. Reduced productivity and increased demand for land threatens the security of the global water-food-energy nexus.

- Globally, annual ecosystem service value losses of US\$ 6.3 to 10.6 trillion occur from land degradation, representing $10-17 \%$ of the world's GDP.

- Ensuring a sustained delivery of land-related ecosystems across degraded and currently degrading areas can help to alleviate poverty and foster economic prosperity, contributing to the Sustainable Development Goals.

- Annually, US\$ 75.6 trillion can be gained from transforming global policies that enable sustainable land management.

- Economic rates of return of 5\%-50\% have been documented for such projects as large-scale rangeland restoration (Jordan), crop residue burning control (Georgia), soil fertility management (Kenya), and agroforestry and reforestation (Mali and Sudan). 


\section{Introduction}

Land degradation is occurring rapidly at a time of growing need for fertile soil and healthy ecosystems. Multi-scale solutions that ensure economic and environmental sustainability are needed. Scientific advances have been driven by UNU-INWEH which between 2012 and 2016 has been responsible for the scientific coordination of the global Initiative on the Economics of Land Degradation (ELD). The Initiative aims to create awareness of the economic case for sustainable land management - preventing the loss of this valuable natural capital while addressing water, food and energy security (ELD Initiative, 2015a).

\section{Sustainable development goals and land degradation neutrality}

In 2015, United Nations endorsed the Sustainable Development Goals (SDGs) 2015-2030 framework. Part of this framework is Land Degradation Neutrality (LDN) - SDG target 15.3. LDN represents a state where in the amount and quality of land resources, necessary to support ecosystem services, remain stable or increase over time. It is based on the idea that economic benefits from taking action to prevent or reverse land degradation - from Sustainable Land Management (SLM) practices - are higher than the costs of action (Favretto et al., 2016; UNCCD, 2015).

Productive land is a prerequisite for reaching at least 8 of the SDGs (i.e., SDG \#1 on poverty reduction, \#2 on food security and sustainable agriculture, \#5 on gender equality, \#6 on water, \#7 on sustainable energy, 10\# on reduced inequality, \#14 on reduced marine pollution from land-based activities, and \#16 on inclusive societies requiring adequate land rights).

\section{Valuing land and its ecosystems: the ELD 6+1 steps approach}

The services provided by the world's ecosystems are classified as provisioning, supporting, regulating and cultural. Economic tools allow humanity to value land and its ecosystems and to estimate the costs of degradation and the benefits of sustainable land management, with a view to inform land use management decisions (Favretto et al., 2017).

The " $6+1$ steps" is a multi-level, holistic methodology adopted by the ELD Initiative to identify the most economically desirable SLM options (ELD Initiative, 2015b). The six steps include i) inception, ii) assessment of the geographical characteristics of the study area, iii) identification of the types of ecosystem services, iv) assessment of the roles of ecosystem services and economic valuation, v) identification of land degradation patterns and pressures, and vi) cost-benefit analysis (CBA). The following " +1 " is taking action. The methodology guides a CBA of the impact of alternative land management options (Box 1).

\section{Box 1. Sustainable land management in Zarqa River Basin, Jordan: A Cost-Benefit Analysis}

The ELD Initiative case study in the Zarqa River Basin, Jordan adopted the $6+1$ steps approach and carried out a CBA of large-scale rangeland restoration through the Hima system (i.e., traditional rangeland management based on communal sharing). The study found that, over a 25-year horizon, the potential benefits of large-scale rangeland restoration outweigh the costs of action. The Net Present Value (NPV) benefit to pastoral communities accounts for US\$17 million at a discount rate of $5 \%$, while the Benefit-Cost Ratio is 2.1, indicating that pastoral communities could enjoy US\$2 of benefit for every US\$ 1 they invest in implementing Hima restoration. The study demonstrated that Hima restortion will positively impact hydrological services. An ArcSWAT hydrological model was developed to predict the impact of land management practices on water. A significant change in the level of aquifer recharge is observed within approximately five years after establishment of the system. With an estimated economic value of $2.8 \mathrm{US} \$ / \mathrm{m}^{3}$ of water, the total NPV over a 25-year time horizon of groundwater infiltration as a result of Hima restoration accounts for US\$265.8 million. This is equivalent to an annuity value of US\$18.8 million.

Myint M, Westerberg V. 2015. An economic valuation of a large-scale rangeland restoration project through the Hima system in Jordan. Nairobi/Bonn IUCN / ELD Initiative. 
Policy incentives and market-based mechanisms to promote sustainable land management

A range of Incentive and Market-Based Mechanisms (IMBMs) can help correct market failures and incentivize sustainable land management. These include: (i) public payment schemes, (ii) open trading under regulation, (iii) self-organizised private deals, and (iv) eco-labelling. An enabling environment and consideration of the specific context (i.e., biophysical, political, socio-economic, legal, financial, and technical) are crucial in the effective implementation of these instruments (Box 2).

When selected with a thorough understanding of the costs and benefits of action vs. inaction (i.e., business-as-usual) at all relevant levels, a mix of
IMBMs can incentivize sustainable land management, e.g., a deal between a farmer and a private bottler of natural mineral water to promote land management practices that ensure high quantity or quality water downstream.

In the case of payments for investments in conservation, governments provide payments to landowners, based on the investments made per unit of area, to promote sustainable land management. E.g., under the Florida Ranchlands Environmental Services project in the US, cattle ranchers are paid by state agencies to increase water storage and reduce nutrient loading in their land management. Such incentives discourage the development of more intensive agriculture, spending fewer public funds than would be needed to achieve the same goals through infrastructural investments.

Box 2. Estimating the economic impacts of market-based mechanisms for land conservation: the case of wetlands restoration in the Mississippi Alluvial Valley

The Mississippi Alluvial Valley in the US experienced decades of hydrological alteration and agricultural expansion, resulting in a loss of 7.2 million hectares of bottomland hardwood forest between the early 1900s and the 1980s. This resulted in major ecological consequences, including degradation of water quality, and loss of wildlife habitat and flood storage. Through the US voluntary Wetlands Reserve Federal Program (WRP), financial incentives to landowners were provided to restore wetlands and retire marginal farmlands from agricultural production. Evaluation oftheWRP wascarriedoutbyintegratingecosystemservicefunctionmeasurements, environmental-economic modeling. Ecosystem services were quantified and monetized in cropland and restored wetlands. Findings indicate that restoring wetlands in the Mississippi River Valley has a social value (ranging between US\$1,435 and US\$1,486/ha/ year) that outmatches the alternative use in agriculture, with public expenditure surpassed by social value within 1 year of implementation.

Jenkins W, Murray B, Kramer R, Faulkner S. 2010. Valuing ecosystem services from wetlands restoration in the Mississippi Alluvial Valley. Ecological Economics 69: 1051-1061.

\section{Recommendations}

- Protection of soils and restoration of degraded land (SDG 15) should be promoted as key objectives towards the achievement of all SGDs, particularly \# 1, 2, 5, 6, 7, 10, 14 and 16. SLM should become a primary focus of investments.

- Land policies should integrate multiple values of human well-being with the complex drivers of land degradation. Economic approaches can help recognize the interlinkages between these drivers and identify optimal solutions.

- A holistic approach - such as the ELD 6+1 steps - must be taken to valuing ecosystem services and informing the use of a range of instruments that promote sustainable land management.

- Land degradation issues need to be mainstreamed into inter-sectoral development frameworks. Enabling environments should take into account context-specific factors - i.e. biophysical, socio-economics and legal dimensions. 


\section{References}

ELD Initiative. 2015a. The Value of Land: Prosperous lands and positive rewards through sustainable land management. GIZ: Bonn, Germany. Available from http://eld-initiative.org/.

ELD Initiative. 2015b. ELD Initiative User Guide: A 6+1 step approach to assess the economics of land management. GIZ: Bonn, Germany. Available from http://eld-initiative.org/.

Favretto N, Luedeling E, Stringer LC, Dougill AJ. 2017. Valuing Ecosystem Services in Semi-Arid Rangelands through Stochastic Simulation. Land Degrad. Dev. 28: 65-73.

Favretto N, Stringer LC, Dougill AJ, Dallimer M, Perkins JS, Reed MS, Atlhopheng JR, Mulale K. 2016. Multi-Criteria Decision Analysis to identify dryland ecosystem service trade-offs under different rangeland land uses. Ecosyst. Serv. 17: 142-151.

UNCCD. 2015. Reaping the rewards: Financing land degradation neutrality. Bonn: United Nations Convention to Combat Desertification.

Author: Nicola Favretto

Editors: Vladimir Smakhtin, Terry Collins

Suggested citation: Favretto, N., 2017. Sustainable Development Goals and the Economics of Land Degradation. UNU-INWEH Policy Brief, Issue 1. United Nations University Institute for Water Environment and Health. Hamilton, Ontario, Canada.

Photo credit: Nicola Favretto Layout and design: Kelsey Anderson

ISBN: 978-92-808-6081-8

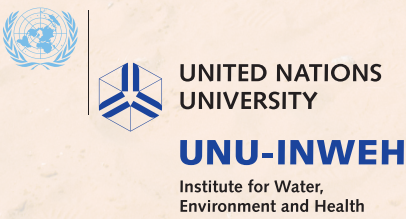

